\title{
Quality of life in young adult patients with a cardiogenetic condition receiving an ICD for primary prevention of sudden cardiac death
}

\author{
Citation for published version (APA): \\ Verkerk, A. J., Vermeer, A. M., Smets, E. M., Dekker, L. R. C., Wilde, A. A., Van Langen, I. M., Christiaans, I., \& \\ Nieuwkerk, P. T. (2015). Quality of life in young adult patients with a cardiogenetic condition receiving an ICD' for \\ primary prevention of sudden cardiac death. Pacing and Clinical Electrophysiology: PACE, 38(7), 870-877. \\ https://doi.org/10.1111/pace.12649
}

DOI:

10.1111/pace.12649

Document status and date:

Published: 01/07/2015

\section{Document Version:}

Publisher's PDF, also known as Version of Record (includes final page, issue and volume numbers)

\section{Please check the document version of this publication:}

- A submitted manuscript is the version of the article upon submission and before peer-review. There can be important differences between the submitted version and the official published version of record. People interested in the research are advised to contact the author for the final version of the publication, or visit the DOI to the publisher's website.

- The final author version and the galley proof are versions of the publication after peer review.

- The final published version features the final layout of the paper including the volume, issue and page numbers.

Link to publication

\footnotetext{
General rights

- You may freely distribute the URL identifying the publication in the public portal. follow below link for the End User Agreement:

www.tue.nl/taverne

\section{Take down policy}

If you believe that this document breaches copyright please contact us at:

openaccess@tue.nl

providing details and we will investigate your claim.
}

Copyright and moral rights for the publications made accessible in the public portal are retained by the authors and/or other copyright owners and it is a condition of accessing publications that users recognise and abide by the legal requirements associated with these rights.

- Users may download and print one copy of any publication from the public portal for the purpose of private study or research.

- You may not further distribute the material or use it for any profit-making activity or commercial gain

If the publication is distributed under the terms of Article $25 \mathrm{fa}$ of the Dutch Copyright Act, indicated by the "Taverne" license above, please 


\title{
Quality of Life in Young Adult Patients with a Cardiogenetic Condition Receiving an ICD for Primary Prevention of Sudden Cardiac Death
}

\author{
AGNES J. VERKERK, R.N.,* ALEXA M. VERMEER, M.D.,† ELLEN M. SMETS, Ph.D.,‡ \\ LUKAS R. DEKKER, M.D., PH.D.,§ ARTHUR A. WILDE, M.D., PH.D., * \\ IRENE M. VAN LANGEN, M.D., PH.D.,II IMKE CHRISTIAANS, M.D., PH.D.,† \\ and PYTHIA T. NIEUWKERK, PH.D.‡ \\ From the ${ }^{*}$ Department of Clinical and Experimental Cardiology, Heart Centre AMC, Academic Medical Center, \\ Amsterdam, the Netherlands; +Department of Clinical Genetics, Academic Medical Center, Amsterdam, the \\ Netherlands; ‡Department of Medical Psychology, Academic Medical Center, Amsterdam, the Netherlands; \\ $\S$ Department of Cardiology, Catharina Hospital, Eindhoven, the Netherlands; and IDepartment of Clinical Genetics, \\ University Medical Center Groningen, Groningen, the Netherlands
}

Background: Prophylactic implantable cardioverter defibrillator (ICD) therapy prevents sudden cardiac death (SCD) among young adults with cardiogenetic conditions, but might reduce quality of life (QoL) due to potential device complications, ongoing medical appointments, and lifestyle restrictions. We investigated QoL in the first year after ICD implantation for the primary prevention of SCD and compared QoL scores with population norms.

Methods: Consecutive patients with cardiogenetic conditions (aged 18-50 years) referred to the Academic Medical Center in Amsterdam to receive ICD therapy for the primary prevention of SCD between 2007 and 2009 were eligible. Patients completed questions about QoL (Short-Form 36 Health Survey; SF-36), depressive symptoms (Center for Epidemiologic Studies Depression scale; CES-D), anxiety (State-Trait Anxiety Inventory; STAI), and the impact of receiving ICD therapy on lifestyle and work, shortly before ICD implantation and after 2 months, 6 months, and 12 months.

Results: Thirty-five of 47 eligible patients participated. QoL was significantly reduced shortly before and 2 months after ICD implantation but improved over time and was comparable with population norms at 6 months and 12 months after ICD implantation. Yet, only about half of the patients believed they had a normal life like everyone else, and $28 \%$ had lost or changed their job due to their cardiogenetic condition and ICD therapy.

Conclusions: Receiving a diagnosis of a cardiogenetic condition and subsequent ICD implantation was accompanied with a temporarily reduced QoL and a significant negative impact on professional life. Clinicians should inform their patients of the possible QoL consequences when deciding about ICD implantation in primary prevention of SCD in cardiogenetic conditions. (PACE 2015; 38:870-877)

quality of life, cardiogenetic conditions, implantable cardioverter defibrillators, health-related quality of life

\section{Introduction}

Prophylactic implantable cardioverter defibrillator (ICD) therapy is an established intervention among young adults with cardiogenetic conditions at risk for sudden cardiac death (SCD). ICD therapy comes, however, with potential risks,

Address for reprints: Pythia Nieuwkerk, Ph.D., Department of Medical Psychology (J3-219-1), Academic Medical Center, Meibergdreef 9, 1105 AZ, Amsterdam. Fax: 31-20-5669104; e-mail: p.t.nieuwkerk@amc.uva.nl

Received December 29, 2014; revised March 3, 2015; accepted April 12, 2015.

doi: 10.1111/pace.12649 including short-term procedural complications such as infection and vascular complications, and lead-related problems during follow-up. ${ }^{1}$ These potential risks of ICD therapy could have a negative effect on patients' quality of life (QoL). QoL is generally considered to encompass patients' physical, psychological, and social functioning, which can be affected by both disease and treatment. Studies in several settings have shown that QoL is also influenced adversely in patients who experience ICD shocks, regardless of whether shocks are appropriate or inappropriate. ${ }^{2}$ Additionally, ICD therapy has been associated with an increased incidence of anxiety and depression and impaired QoL both in adult and pediatric populations. ${ }^{3-8}$ 
The issue of QoL is particularly important in primary prevention, in which the willingness to accept a potentially unpleasant therapy for an uncertain future benefit may be low. ICD therapy for the primary prevention of SCD is not expected to improve QoL in the short term, but on the contrary entails the possibility of harm from either psychological or physical complications of therapy.

Primary prevention ICD therapy could have a particular negative impact on QoL among young adult patients. ${ }^{9}$ Procedural risks of ICD implantation may be lower in a younger population and, as they are characterized by lower morbidity and mortality rates, the potential benefit of ICD therapy may be higher compared to an older population. On the other hand, younger patients have a higher risk of receiving inappropriate ICD shocks than older patients. ${ }^{10}$ Moreover, studies so far suggest that although older patients with ICDs have decreased physical functioning, more comorbid illness, and worse symptoms that negatively impacted QoL, younger patients with ICDs tend to have more difficulty with adjusting to the ICD. ${ }^{9,11,12}$ Compared to older patients, younger patients face decades of life with the ICD and its restrictions on physical functioning, body image, driving or working life, and the ongoing medical appointments may have a more negative impact on their QoL.

To date, evidence on the impact on QoL of receiving an ICD for the primary prevention of SCD among young adults is limited. Most studies have investigated QoL in a cross-sectional study design among populations including both younger and older primary and secondary prevention patients who had their ICD implanted up to 5 years ago. $^{9,12,13-15}$ Several studies have investigated the effect of ICD implantation on QoL in a prospective design, but the mean age of patients enrolled in these studies was older than 50 years. ${ }^{1,16-19}$ Thus, it remains largely unclear how an ICD affects QoL in young adult patients who receive a primary prevention ICD.

Therefore, we aimed to prospectively investigate the impact on QoL in the first year after receiving an ICD for the primary prevention of SCD among young adults between 18 years and 50 years of age with a cardiogenetic condition. Furthermore, we compared their QoL scores with available population norms.

\section{Methods \\ Participants and Procedure}

Participants were adult patients, aged between 18 years and 50 years, who were referred to the Department of Cardiology of the Academic
Medical Center in Amsterdam, the Netherlands, to receive ICD therapy for the primary prevention of SCD between December 2007 and March 2009. Eligible patients were diagnosed or presumed to have a cardiogenetic condition or a genetic defect predisposing for such a condition. In the latter case, the family history had to indicate at least one first-degree family member with SCD or aborted SCD. Patients with cognitive impairment, a comorbid condition resulting in a life expectancy of less than 6 months, or no informed consent were excluded from participation. Consecutive eligible patients who were scheduled for ICD implantation were asked to participate in the study. Participation in the study consisted of completing a questionnaire on QoL prior to ICD implantation and at 2 months, 6 months, and 12 months after implantation. Patients completed the questionnaire at home and returned the questionnaire in a prestamped envelope.

The study was exempted for ethical approval by the central ethics committee of our institution. The committee decided that the Medical Research Involving Human Subjects Act does not apply to the study. The study was conducted according to the Declaration of Helsinki Principles of 1983. Informed consent was obtained from all participating patients.

\section{Measurements}

Information on demographic (age, gender, working status, having a partner and/or children, education, driver's license) and clinical variables (underlying cardiogenetic condition, symptoms before ICD implantation, prescribed medication after ICD implantation, delivery of appropriate or inappropriate ICD shocks) were obtained from self-report questions in the first questionnaire and medical records, respectively.

QoL was assessed using the medical outcomes study Short-Form 36 Health Survey (SF-36). ${ }^{20}$ The SF-36 contains 36 items covering eight dimensions of QoL: physical functioning, role limitations owing to physical problems, role limitations owing to emotional problems, social functioning, mental health, health perceptions, vitality, and bodily pain. Scores for each domain range from 0 to 100, with higher scores reflecting better QoL. Normative data from the Dutch general population are available. ${ }^{21}$

Depressive symptoms were assessed using the Center for Epidemiologic Studies Depression scale (CES-D). ${ }^{22}$ The CES-D contains 20 items asking about depressive symptoms in the past week. Scale scores range from 0 to 60 , with higher scores indicating a higher level of depressive symptoms. A score of 16 or higher has been proposed to 
indicate clinically significant levels of depressive symptoms.

We assessed the presence of symptoms of general anxiety using the state scale of the StateTrait Anxiety Inventory (STAI). The STAI state scale consists of 20 items. The scale ranges from 20 to 80, with higher scores indicating higher levels of state anxiety. ${ }^{23}$ A cut-off score of 40 or higher was previously used to indicate clinically elevated levels of general anxiety among ICD and myocardial infarction patients. ${ }^{24}$

We designed a number of statements to explore the impact of receiving ICD therapy for a cardiogenetic condition. The topics covered by the statements were made up by an expert panel consisting of physicians and nurses with extensive experience with young adult ICD patients. The statements were the following: the ICD makes me feel protected against my cardiogenetic condition, the ICD has more negative than positive effects, I worry about my ICD firing when nobody is around, I feel less attractive because of my ICD, my ICD influences the way I dress, I can no longer do the things I enjoy, and I have a normal life like everyone else. It also included the following statements: my cardiogenetic condition and ICD therapy have a negative influence on my professional career, have an important influence on the decision to have (more) children, and have a negative impact on the relationship with my partner. Response options for each statement were: agree, neither agree or disagree, disagree, and not applicable.

We asked patients if they had lost their job or changed jobs due to their cardiogenetic condition and ICD therapy. We also asked patients if they were temporarily unable to do their job or had reduced their hours of paid work because of their cardiogenetic condition and ICD therapy. Response options for these questions were: yes, no, or not applicable.

The questionnaire on QoL administered shortly before ICD implantation included the questions about demographics, the SF-36, CES$\mathrm{D}$, and the STAI. The questionnaire administered at 2 months, 6 months, and 12 months after ICD implantation included the SF-36, CES-D, STAI, and the statements and questions about the ICD.

\section{Statistical Analyses}

We calculated mean scale scores for the SF-36 dimensions, the CES-D, and the STAI. The eight dimensions of the SF-36 score were converted to standard scores on the basis of the scores of an age- and gender-matched representative reference sample of the Dutch population. Standard scores were calculated by dividing the difference between the patients' SF-36 score and the mean age- and gender-matched score of the reference population by the standard deviations of the reference population. A standard score thus indicates how many standard deviations the observed SF-36 score falls below or above the score of the reference population. Consequently, scores of the reference population are set at zero. Given the similarity with effect sizes (ES) calculation, mean standard scores of $0.20,0.50$, and 0.80 were considered to indicate small, medium, and large deviations from the reference population, respectively. ${ }^{25}$ Additionally, standard scores of all patients were compared to the Dutch general population using one sample $t$-tests. We calculated the percentage of patients who had a score equal or higher than the cut-off on the CES-D and the STAI. We investigated the course of these percentages over time using generalized estimating equations.

We investigated the course of mean scores on the SF-36, CES-D, and STAI over time using mixed linear models. We included time as fixed effect. To account for the fact that multiple patients from the same family could participate, we included family as random effect. To explore the impact of experiencing an ICD shock, we repeated the analyses including having experienced an ICD shock in the period preceding questionnaire completion as time-dependent covariate.

We calculated the percentage of patients who agreed with or responded confirmative to the statements or questions about the ICD and investigated the course of these percentages over time using generalized estimating equations.

All statistical calculations were conducted using SPSS version 20 (IBM Corp., Armonk, NY, USA). Two-sided $\mathrm{P}$ values $<0.05$ were considered to indicate statistical significance.

\section{Results}

Between December 2007 and March 2009, a total of 47 consecutive young adult patients referred to receive primary prevention ICD therapy were asked to participate in the study, of whom 45 agreed. ICD implantation was postponed in one patient, four patients failed to complete the baseline questionnaire, and five patients failed to complete the follow-up questionnaires, resulting in a sample size of 35 patients. There were no significant differences between 35 patients who participated in the study and 10 patients who did not participate in age (mean age: 37 years vs 34 years, $\mathrm{P}=0.044$ ) and gender (percentage of males: $50 \%$ vs $51 \%, P=1.0$ ). The median (interquartile range) duration of time between receiving a diagnosis of a cardiogenetic condition and ICD implantation was 95 days (31-163 days; $\mathrm{n}=20$ ). Characteristics at baseline are shown in Table I. In addition to the prescribed medicines shown in Table I, one patient was prescribed antiretroviral medication, 
Table I.

Characteristics at Baseline

\begin{tabular}{lc}
\hline & $\mathbf{n}=\mathbf{3 5}$ \\
\hline Age, mean (SD) & $36.7(8.6)$ \\
Males, number (\%) & $18(51 \%)$ \\
Working status & \\
$\quad$ Employed & $29(82 \%)$ \\
Student & $3(9 \%)$ \\
Unemployed/not working & $3(9 \%)$ \\
For work dependent on driver license & \\
Yes & $15(43 \%)$ \\
No & $17(49 \%)$ \\
Not applicable & $3(8 \%)$ \\
Marital status & \\
Married & $25(71 \%)$ \\
Divorced & $3(9 \%)$ \\
Single & $6(18 \%)$ \\
Unknown & $1(2 \%)$ \\
Has children & $24(69 \%)$ \\
Cardiogenetic condition & \\
DPP6 & $21(60 \%)$ \\
Brs & $4(11 \%)$ \\
LQTS & $1(3 \%)$ \\
HCM & $5(14 \%)$ \\
ARVC & $3(9 \%)$ \\
Family history of (resuscitated) SCD & $1(3 \%)$ \\
\hline
\end{tabular}

$(n=33)$

\begin{tabular}{lc} 
Symptoms & \\
No symptoms & $24(69 \%)$ \\
Dizziness & 1 \\
Fainting & 5 \\
Palpitations & 4 \\
Chest pain & 3 \\
Hyperventilation & 1 \\
Arrhythmias & 1 \\
\hline
\end{tabular}

(n=29)

Medication
No medication
Antihypertensive
$\beta$-Blocker
Diuretics
ACE inhibitor

ARVC = arrhythmogenic right ventricular cardiomyopathy; Brs = Brugada syndrome; DPP6 = dipeptidyl-peptidase 6; LQTS = long QT-interval syndrome; $\mathrm{HCM}=$ hypertrophic cardiomyopathy; $\mathrm{SCD}=$ sudden cardiac death; $\mathrm{SD}=$ standard deviation .

one patient antimigraine medication, and one patient an antihistamine and a bronchodilator.

\section{QoL Compared with Norm Scores}

Patients completed the baseline questionnaire on average 3 days prior to ICD implantation. Shortly before ICD implantation, patients had a significantly worse QoL on the SF-36 dimensions vitality ( $\mathrm{ES}=-0.68)$, social functioning $(\mathrm{ES}=$ $-0.54)$, role functioning emotional $(E S=-0.66$ ), and mental health ES $=-0.78$ ) than age- and gender-matched Dutch population norms, with ES being medium to large (Fig. 1). Two months after ICD implantation, patients had significantly worse QoL on all SF-36 dimensions with the exception of bodily pain and role-emotional compared with the Dutch population norms. The deviation from the Dutch population norms was most pronounced in magnitude for role-physical (ES $=-1.14$ ), vitality ( $\mathrm{ES}=-0.53$ ), and social functioning $(\mathrm{ES}=-0.60)$. At six months and 12 months after ICD implantation, patients' QoL on the SF-36 dimensions was not significantly worse than ageand gender-matched Dutch population norms.

Before ICD implantation, 29\% of the patients had a depression score (CES-D) higher than the cut-off score of 16. After 2 months, 6 months, and 12 months, this percentage was $23 \%, 9 \%$, and $13 \%$, respectively (time effect, $\mathrm{P}=0.12$ ).

Before ICD implantation, $71 \%$ of the patients had an anxiety score (STAI state) higher than the cut-off of 40. After 2 months, 6 months, and 12 months, this percentage was $40 \%, 32 \%$, and $34 \%$, respectively (time effect, $\mathrm{P}=0.001$ ).

\section{QoL over Time}

We observed a statistically significant change over time in mean scores on physical functioning $(\mathrm{P}=0.041)$, role functioning physical $(\mathrm{P}<$ $0.001)$, bodily pain $(\mathrm{P}=0.002)$, social functioning $(\mathrm{P}=0.013)$, mental health $(\mathrm{P}<0.001)$, role functioning emotional $(\mathrm{P}=0.005)$, vitality $(\mathrm{P}=$ 0.006), depressive symptoms $(P=0.001)$, and anxiety $(\mathrm{P}<0.001)$. For physical functioning, role functioning physical (Fig. 2A), and bodily pain, QoL was significantly worse at 2 months following ICD implantation than at 12 months following ICD implantation. For social functioning (Fig. 2B), mental health, and role functioning emotional, QoL was significantly worse before and at 2 months following ICD implantation than at 12 months following ICD implantation. Vitality was significantly worse, and depressive symptoms (Fig. 2C) and anxiety (Fig. 2D) were significantly higher before ICD implantation than at 12 months after ICD implantation.

A total of three patients experienced an ICD shock during the 12-month follow-up period, which was delivered inappropriately in two patients and appropriately in one patient. Patients 

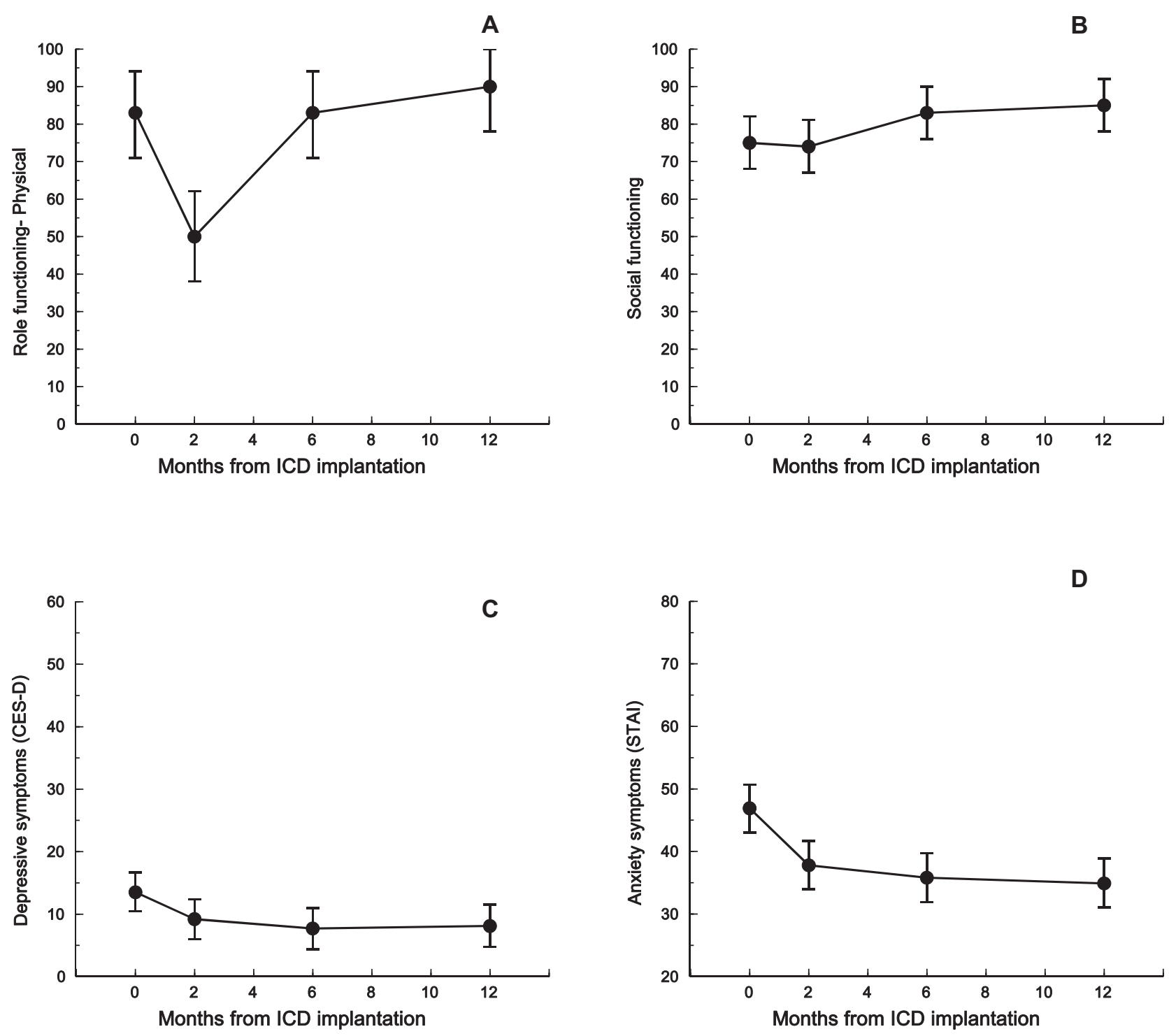

Figure 1. Quality of life in ICD patients compared with age- and gender-matched Dutch general population. A= role functioning physical; $B=$ social functioning; $C=$ depressive symptoms (CES-D); $D=$ anxiety symptoms (STAI); ICD = implantable cardioverter defibrillator.

experiencing an inappropriate ICD shock in the period prior to questionnaire completion reported worse QoL on the subsequent questionnaire for physical functioning $(\mathrm{P}<0.001)$, bodily pain $(\mathrm{P}=$ 0.050), social functioning $(\mathrm{P}=0.016)$, and vitality $(\mathrm{P}=0.08)$ than patients not experiencing ICD shocks. The negative impact on QoL was less pronounced when the patient experiencing an appropriate shock was also considered.

The percentage of questionnaires on which patients agreed with statements about the ICD were the following: the ICD makes me feel protected against my cardiogenetic condition:
$87 \%$; my ICD has more negative than positive effects: $11 \%$; I worry about my ICD firing when nobody is around: $22 \%$; I feel less attractive because of my ICD: $8 \%$; my ICD influences the way I dress: $16 \%$; I can no longer do the things I enjoy: $19 \%$; and I have a normal life like everyone else: $52 \%$.

The percentage of patients who agreed with the additional statements about their ICD did not change significantly over time. We therefore report the mean percentage of patients across time points. The percentage of patients agreeing with additional statements were the following: 

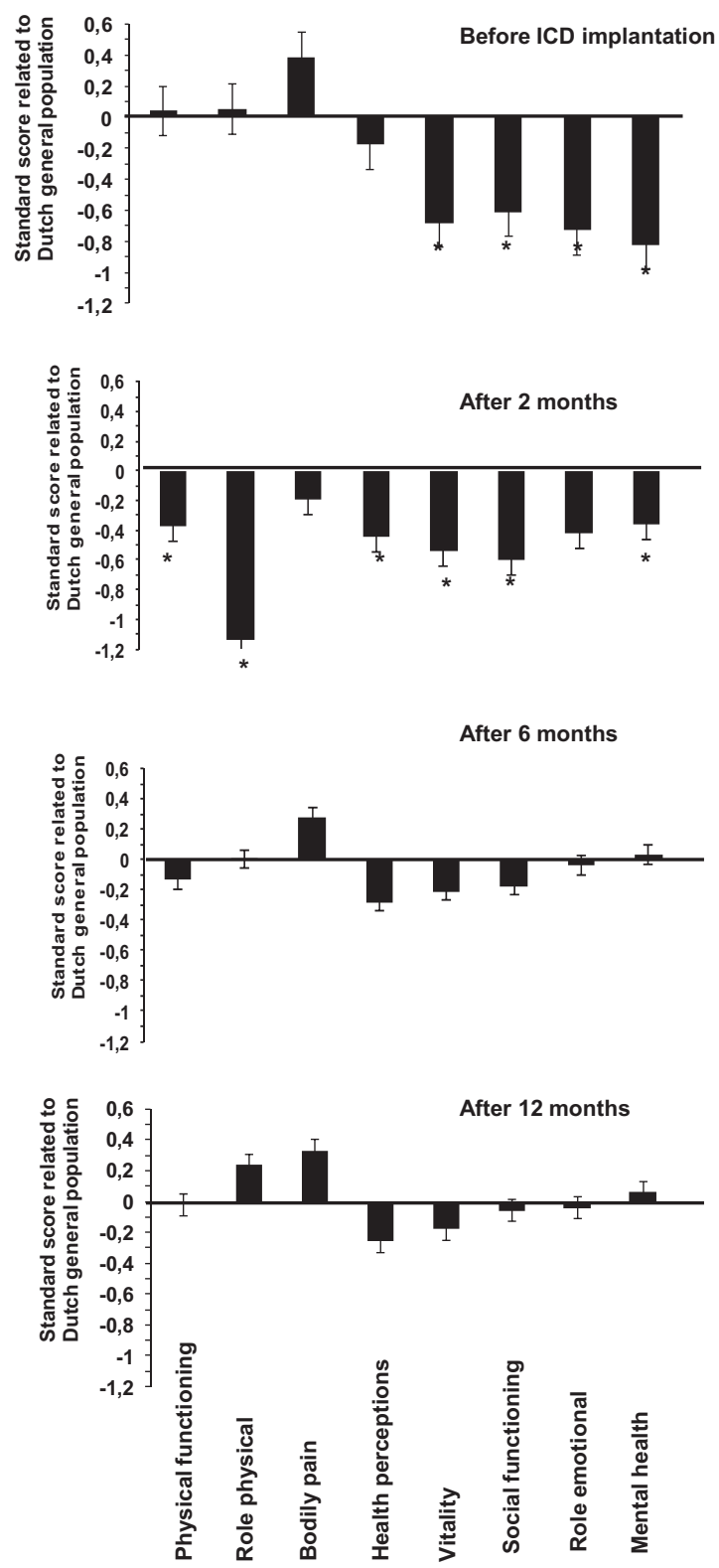

Figure 2. Quality of life in ICD patients before and after ICD implantation. $A=$ before ICD implantation; $B=$ after 2 months; $C=$ after 6 months; $D=$ after 12 months; $I C D=$ implantable cardioverter defibrillator.

my cardiogenetic condition and ICD therapy: have a negative influence on my professional career: $34 \%$; have an important influence on the decision to have (more) children: $36 \%$; and have a negative impact on the relationship with my partner: $2 \%$.

A total of 29 patients had a paid job at baseline. Of those, eight patients $(28 \%)$ had lost their job or changed jobs due to their cardiogenetic condition and ICD therapy. Some patients spontaneously exemplified their responses. One patient mentioned previously being a technician working on hoisting cranes at 7-9 $\mathrm{m}$ above the ground and now having become a house man. Another patient mentioned previously working as police officer on a patrol car and now working as an adviser. Yet another patient mentioned no longer being allowed to work as a chauffeur due to driving license restrictions for persons with ICDs. Five $(17 \%)$ other patients were temporarily unable to do their job. A total of nine patients $(31 \%)$ reported that they reduced their hours of paid work.

\section{Discussion}

In our prospective study among young adult patients with a cardiogenetic condition receiving ICD therapy for the primary prevention of SCD, QoL was significantly reduced shortly before and 2 months after ICD implantation but improved over time and was comparable with population norms at 6 months and 12 months after ICD implantation. Nevertheless, only about half of the patients believed they had a normal life like everyone else, about one-third experienced elevated levels of anxiety, about one-third believed their cardiogenetic condition and ICD therapy had a negative effect on their professional life, and $28 \%$ had lost their job or changed jobs due to their cardiogenetic condition and ICD therapy.

To the best of our knowledge, the impact on QoL among young adults ( $<50$ years) receiving an ICD for primary prevention has not previously been investigated in a prospective longitudinal study. A few cross-sectional studies, assessing QoL several years after ICD implantation, have included varying percentages of young primary prevention patients among their entire study population. ${ }^{9,12,14,15}$ These cross-sectional studies have shown that up to 5 years after ICD implantation, the vast majority of patients have levels of QoL, anxiety, and depression that are within the range of normative general population data. Results from this study are consistent with these prior results, and add that levels of QoL, anxiety, and depression return within the normal range already 6-12 months after ICD implantation in the majority of patients, although about onethird of the patients experienced persistently elevated levels of anxiety. Despite having levels of QoL within the normal range, considerable numbers of patients in this study and in a previous study $^{15}$ reported problems in their professional life. Previously, it was found that reduced QoL related to ICD implantation is greater in active young patients and that these patients frequently complain about alteration of their professional career. ${ }^{15}$ Results from this study are in line with these findings. 
We found that experiencing an ICD shock appeared to have a significant negative impact on the more physical aspects of QoL, such as physical functioning, bodily pain, vitality, and social functioning rather than on the more psychological aspects, such as mental health, anxiety, and depression. Studies reporting about the association between experiencing ICD shocks and QoL have reported divergent results. In some studies, it was found that ICD shocks were associated with posttraumatic stress ${ }^{9}$ and anxiety symptoms, ${ }^{9,12}$ whereas others have found associations with a reduced physical QoL but not with a reduced mental health or increased anxiety/depression symptoms. ${ }^{17}$ Because the numbers of patients experiencing shocks are usually low, the specific effects on QoL detected within studies may vary due to limited statistical power.

This study has several limitations. We cannot distinguish between the impact on QoL of receiving a diagnosis of a cardiogenetic condition and of the ICD implantation. Half of the patients had received their diagnosis only up to 3 months ago. Because QoL was already significantly impaired compared with general population norms shortly before ICD implantation, it can be inferred that receiving such diagnosis and/or the knowledge that ICD therapy is required already has a significant negative impact on QoL. It is known that receiving a cardiogenetic diagnosis also has a temporarily negative impact on QoL. ${ }^{26}$ Patients completed the baseline questionnaire on average 3 days before ICD implantation. Consequently, the baseline assessment was most likely also biased by preimplantation distress. Obtaining QoL data at the time of diagnosis, but remote from the time of ICD implantation, may give a better picture of the separate impact on patient's QoL of the diagnosis and ICD implantation. However, this was not feasible in this study since we only recruited patients once they became eligible for ICD implantation. Moreover, dipeptidyl-peptidase 6 (DPP6) patients became eligible for ICD implantation as soon as they received their diagnosis with a consequent short duration between diagnosis and ICD implantation.

In spite of having QoL within the normal population range as from 6 months after ICD implantation, only about half of the patients believed they had a normal life like everyone else. The latter may have been due to the problems patients experienced in their professional life. It could also suggest that the SF-36 does not capture the ways in which an ICD decreases QoL in ICD patients. Nowadays, several validated ICD-specific QoL questionnaires exist. However, at the time this study started, that is, in 2007, these questionnaires were not yet widely known and used.
The majority of patients in our study consisted of those with familial ventricular fibrillation due to the DPP6 haplotype. These patients are prone to develop idiopathic ventricular fibrillation. Otherwise, these patients are asymptomatic. Fifty percent of the risk haplotype carriers experienced an event of ventricular fibrillation before the age of $60 .{ }^{27}$ Currently, the implantation of an ICD is the only effective treatment. DPP6 patients and patients with other cardiogenetic conditions have in common the risk of SCD without ICD therapy, and the risk of device complications, ongoing medical appointments, and lifestyle restrictions after ICD implantation which could reduce their QoL. However, unlike DPP6 patients, patients with hypertrophic cardiomyopathy, arrhythmogenic right ventricular cardiomyopathy, long QTinterval syndrome, and Brugada syndrome are still at risk of developing disease-related morbidity after ICD implantation which could have a negative impact on their QoL. We found that DPP6 patients had a better QoL with respect to social functioning, mental health, and role functioning emotional, and had less depressive symptoms than patients with other cardiogenetic conditions (data not shown). These effects remained even after adjustment for age and gender. Possibly, this better QoL in DPP6 patients can be explained by the absence of the risk of developing disease-related morbidity after ICD implantation. The impact on QoL of ICD therapy may thus be underestimated in this study.

Only a small number of patients were included in our study. As cardiogenetic conditions are rare, and only a small subset of clinically diagnosed individuals requires an ICD, the number of individuals meeting inclusion criteria was limited. Another limitation is that this is a singlecenter study.

In conclusion, among young adult patients with a genetic predisposition for SCD, the decision to implant an ICD requires a careful weighing of potential risk and benefits associated with this therapy. With this study, we show evidence about the short-term and longer term consequences for patients' QoL of receiving a diagnosis of having a cardiogenetic condition with subsequent ICD implantation. These results may inform clinicians about the possible QoL consequences when deciding about ICD implantation in primary prevention of SCD in cardiogenetic conditions and they should inform patients accordingly.

Acknowledgments: We would like to thank the participants in this study and Loes Stoets for her contribution to the data collection of the study. 


\section{References}

1. Mark DB, Anstrom KJ, Sun JL, Clapp-Channing NE, Tsiatis AA, Davidson-Ray L Lee KL, et al; Sudden Cardiac Death in Heart Failure Trial Investigators. Quality of life with defibrillator therapy or amiodarone in heart failure. N Engl J Med 2008; 359:999-1008.

2. Borne RT, Varosy PD, Masoudi FA. Implantable cardioverterdefibrilator shocks. Epidemiology, outcomes, and therapeutic approaches. JAMA Intern Med 2013; 173:859-865.

3. Hegel MT, Griegel LE, Black C, Goulden L, Ozahowski T. Anxiety and depression in patients receiving implanted cardioverter -defibrillators: A longitudinal investigation. Int J Psychiatry Med 1997; 27:57-69.

4. Koopman HM, Vrijmoet-Wiersma CM, Langius JN, vanden Heuvel F, Clur SA, Blank CA, Blom NA, et al. Psychological functioning and disease-related quality of life in pediatric patients with an implantable cardioverter defibrillator. Pediatr Cardiol 2012; 33:569-575.

5. Sears SF, Hazelton AG, St Amant J, Matchett M, Kovacs A, Vazquez LD, Fairbrother D, et al. Quality of life in pediatric patients with implantable cardioverter defibrillators. Am J Cardiol 2011; 107:1023-1027.

6. Webster G, Panek KA, Labella M, Taylor GA, Gauvreau K, Cecchin F, Martucello M, et al. Psychiatric functioning and quality of life in young patients with cardiac rhythm devices. Pediatrics 2014; 133:e964-e972.

7. DeMaso DR, Lauretti A, Spieth L, vander Feen JR, Jay KS, Gauvreau K, Walsh EP, et al. Psychosocial factors and quality of life in children and adolescents with implantable cardioverterdefibrillators. Am J Cardiol 2004; 93:582-587.

8. Czosek RJ, Bonney WJ, Cassedy A, Mah DY, Tanel RE, Imundo JR, Singh AK, et al. Impact of cardiac devices on the quality of life in pediatric patients. Circ Arrhythm Electrophysiol 2012; 5:10641072.

9. Ingles J, Sarina T, Kasparian N, Semsarian C. Psychological wellbeing and posttraumatic stress associated with implantable cardioverter defibrillator therapy in young adults with genetic heart disease. Int J Cardiol 2013; 168:3779-3784.

10. Sherrid MV, Daubert JP. Risks and challenges of implantable cardioverter defibrillators in young adults. Prog Cardiovasc Dis 2008; 51:237-263.

11. Caroll SL, Markle-Reid M, Ciliska D, Conolly SJ, Arthur HM. Age and mental health predict early device-specific quality of life in patients receiving prophylactic implantable defibrilators. Can J Cardiol 2012; 28:502-507.

12. James CA, Tichnell C, Murray B, Daly A, Sears SF, Calkins H. General and disease-specific psychosocial adjustment in patients with arrhythmogenic right ventricular dysplasia/cardiomyopathy with implantable cardioverter defibrillators: A large cohort study. Circ Cardiovasc Genet 2012; 5:18-24.

13. Bilge AK, Ozben B, Demircan S, Cinar M, Yilmaz E, Adalet K. Depression and anxiety status of patients with implantable cardioverter defibrillator and precipitating factors. Pacing Clin Electrophysiol 2006; 29:619-626.

14. Groeneveld PW, Matta MA, Suh JJ, Yang F, Shea JA. Quality of life among implantable cardioverter-defibrillator recipients in the primary prevention therapeutic era. Pacing Clin Electrophysiol 2007; 30:463-471.

15. Probst V, Plassard-Kerdoncuf D, Mansourati J, Mabo P, Sacher F, Fruchet C, Babuty D, et al. The psychological impact of implantable cardiovarter defibrillator implantation on Brugada syndrome patients. Europace 2011; 13:1034-1039.

16. Sweeney MO, Wathen MS, Volosin K, Abdalla I, DeGroot PJ, Otterness MF, Stark AJ. Appropriate and inappropriate ventricular therapies, quality of life, and mortality among primary and secondary prevention implantable cardioverter defibrillator patients: Results from the Pacing Fast VT REduces Shock ThErapies (PainFREE Rx II) trial. Circulation 2005; 111:28982905.

17. Kapa S, Rotondi-Trevisan D, Mariano Z, Aves T, Irvine J, Dorian $\mathrm{P}$, Hayes DL. Psychopathology in patients with ICDs over time: Results of a prospective study. Pacing Clin Electrophysiol 2010; 33:198-208.

18. Pedersen SS, Theuns DA, Muskens-Heemskerk A, Erdman RA, Jordaens L. Type-D personality but not implantable cardioverterdefibrillator indication is associated with impaired health-related quality of life 3 months post-implantation. Europace 2007; 9:675680.

19. Vanden Broek KC, Nyklícek I, Vander Voort PH, Alings M, Denollet J. Shocks, personality, and anxiety in patients with an implantable defibrillator. Pacing Clin Electrophysiol 2008; 31:850857.

20. Ware JE, Snow KK, Kosinski M, Gandek B. SF-36 Health Survey: Manual and Interpretation Guide. Boston, MA, Health Institute, New England Medical Center, 1993.

21. Aaronson NK, Muller M, Cohen PD, Essink-Bot ML, Fekkes M, Sanderman R, Sprangers MA, et al. Translation, validation, and norming of the Dutch language version of the SF-36 Health Survey in community and chronic disease populations. J Clin Epidemiol 1998; 51:1055-1068.

22. Radloff LS. The CES-D scale: A self-report depression scale for research in the general population. Appl Psych Meas 1997; 1:385401.

23. Vander Ploeg HM, Defares PB, Spielberger CD. A Dutch-Language Adaptation of the Spielberger State-Trait Anxiety Inventory. Lisse, the Netherlands, Swets \& Zeitlinger BV, 1980.

24. Kamphuis HC, deLeeuw JR, Derksen R, Hauer RN, Winnubst JA. Implantable cardioverter defibrillator recipients: Quality of life in recipients with and without ICD shock delivery: A prospective study. Europace 2003; 5:381-389.

25. Cohen J. Statistical Power Analysis for the Behavioural Sciences. Mahwah, NJ, Lawrence Erlbaum Associates, 1988.

26. Christiaans I, vanLangen IM, Birnie E, Bonsel GJ, Wilde AA, Smets EM. Quality of life and psychological distress in hypertrophic cardiomyopathy mutation carriers: A cross-sectional cohort study. Am J Med Genet A 2009; 149A:602-612.

27. Postema PG, Christiaans I, Hofman N, Alders M, Koopmann TT, Bezzina CR, Loh P, et al. Founder mutations in the Netherlands: Familial idiopathic ventricular fibrillation and DPP6. Neth Heart J 2011; 19:290-296. 